\title{
PKM PENINGKATAN MUTU PENANGANAN IKAN SEGAR DI PASAR KEDONGANAN DI ERA NEW NORMAL
}

\author{
Pandit, I G S ${ }^{1}$, Wesna Astara, I W' ${ }^{2}$ Permatananda, P. A. N. $\mathrm{K}^{3}$ \\ ${ }^{1}$ Fakultas Pertanian Universitas Warmadewa \\ ${ }^{2}$ Fakultas Hukum Universitas Warmadewa \\ ${ }^{3}$ Fakultas Kedokteran dan Ilmu Kesehatan Universitas Warmadewa \\ igedesuranayapandit@gmail.com,wesnaastara58@gmail.com,nayakasih@gmail.com
}

\begin{abstract}
Abstrak
Desa Kedonganan Kabupaten Badung Bali merupakan salah satu tempat pendaratan dan pemasaran ikan segar, serta tempat kuliner berupa café-café berbasis ikan. Aktivitas masyarakat di Desa Kedonganan berada dibawah Koperasi Unit Desa (KUD) Mina Segara yang dikelola oleh Desa Adat Kedonganan. Para nelayan lokal, maupun nelayan luar dari wilayah Banyuwangi melakukan pendaratan ikan di pantai kedonganan Bali. Aktivitas tersebut di atas dinikmati oleh wisatawan lokal, maupun mancanegara sebagai daerah tujuan wisata. Tujuan PkM adalah untuk meningkatkan pemahaman dan kualitas ikan segar yang dipasarkan, agar para konsumen merasa aman untuk mengkonsumsi. Metode PkM meliputi sosialisasi serta kesepakatan dengan mitra. Pemberian penyuluhan dengan demplot penanganan ikan segar. Hasil PkM berupa pemberian pelatihan penanganan ikan segar dengan penerapan cold chain system serta pemakaian APD di era new normal, yang diikuti penyerahan bantuan steroform, masker, serta apron. Pengelolaan wisata kuliner berbasis ikan dengan kesepakatan Desa Adat Monitoring dan evaluasi telah dilakukan. Dampak program PkM diperoleh peningkatkan pemahaman pedagang tentang penanganan ikan segar dan telah berhasil dengan signifikan. namun keterbatasan pendanaan untuk mengganti sarana cool box masih menjadi kendala untuk memperoleh mutu ikan segar, sehingga diperlukan pemahaman secara kontiniu untuk dapat merubah mainset para pedagang ikan menuju daerah ekowisata pendaratan ikan, pemasaran dan kuliner berbasis ikan.
\end{abstract}

Kata Kunci: Penanganan ikan segar, kesehatan pedagang

\section{PENDAHULUAN}

Desa Kedonganan Kabupaten Badung Bali merupakan salah satu tempat pendaratan dan pemasaran ikan segar, serta tempat kuliner berupa café-café berbasis ikan, seperti ikan bakar, udang bakar, cumi bakar dan aneka jenis ikan lainnya. Semua aktivitas masyarakat di Desa Kedonganan Bali berada dibawah Koperasi Unit Desa (KUD) Mina Segara yang dikelola oleh Desa Adat Kedonganan. Para nelayan lokal, maupun nelayan luar bali seperti dari wilayah Banyuangi melakukan pendaratan ikan di pantai kedonganan Bali. Aktivitas tersebut di atas dinikmati oleh wisatawan lokal, maupun mancanegara sebagai daerah tujuan wisata bahari, mulai aktivitas pendaratan ikan, pemasaran dan pendistribusian ikan ke berbagai tempat di Bali.
Desa Kedonganan dengan luas 1,91 $\mathrm{km}^{2}$ yang terbagi dalam enam banjar adat. Krama pengarep Desa Adat Kedonganan sebanyak 1.198 KK atau 5.111 orang, Berdasarkan jumlah tersebut sebagai pemilik 54 café yang menjual seafood di sepanjang Pantai Kedonganan. Akibat pandemi COVID 19, aktivitas kepariwisataan di Pantai Kedonganan dihentikan per 22 Maret 2020. Pantai ini cukup landai, memiliki hamparan pasir berwarna putih bersih dan ombak yang tenang, dengan garis pantai sepanjang 1020 meter.

Lokasi Desa Kedonganan dapat dicapai dengan mudah mengingat ketersediaan infrastruktur jalan dan sarana transportasi yang memadai. Selain dengan kendaraan pribadi, Desa Kedonganan juga dapat dicapai dengan sarana 
transportasi umum. Kepariwisataan di Pantai Kedonganan sebelum berkembangnya pariwisata, Pantai Kedonganan merupakan pantai nelayan yang kesehariannya lekat dengan kehidupan dan aktifitas nelayan. perkembangan pariwisata di Pantai Kedonganan tidak bisa dipisahkan dari perkembangan pariwisata di daerah Pantai Jimbaran. Pantai Kedonganan dan Jimbaran dikenal sebagai lokasi untuk aktivitas wisata kuliner, sehingga terserapnya produksi ikan pada kelompok-kelompok nelayan Kedonganan yang berlimpah. Pembangunan café tanpa perencanaan yang baik sehingga lingkungan Pantai Kedonganan menjadi tidak rapi, seperti yang terlihat pada gambar berikut.

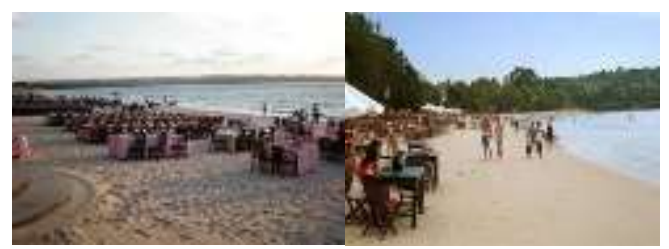

Gambar 1. Suasana Café-café

Berdasarkan hasil observasi yang dilakukan kegiatan pemasaran ikan dan pengelolaan café-café belum berpedoman pada Hazard Analysis Critical Care Point (HACCP), didapatkan bahwa air yang digunakan untuk pencucian ikan di tempat pemasaran ikan berasal dari sumur pompa yang dialirkan melalui pipa ke blok-blok, peralatan pemasaran ikan dicuci sekali hanya ketika kegiatan berlangsung, peralatan pemasaran dan tempat pemasaran tidak diletakkan secara terpisah, kontaminasi saat melakukan proses pemasaran sangat mungkin terjadi karena tidak mencuci tangan dan dilakukan di tempat terbuka, tidak ada tempat mencuci tangan khusus pada setiap blok, sanitasi tidak diperhatikan (lantai berkarat dan dinding berlumut). Saluran pembuangan limbah berada tepat di samping atau di depan blok dan dibiarkan terbuka sehingga berbau, tidak ada perhatian khusus kepada kondisi kesehatan para pedagang yang bekerja.

Adapun tujuan PkM adalah untuk meningkatkan pemahaman para pedagang ikan segar dibidang penanganan ikan segar dan peningkatan kesehatan pedagang serta pengelola wisata kuliner di Desa Kedonganan. Rencana yang akan diterapkan adalah penanganan ikan segar dengan penerapan cold chain system, mengingat ikan laut merupakan komoditi mudah rusak. Pemberian APD untuk meningkatkan kesehatan para pedagang serta pengelolaan wisata kuliner di Desa Kedonganan. Penerapan metode cold chain system dalam proses penanganan bahan baku dianggap tepat seiring dengan hasil penelitian sebelumnya bahwa bahan baku ikan harus diletakkan pada suhu dingin dengan penambahan hancuran es dinilai sebagai teknik penanganan ikan segar yang paling tepat untuk dapat menjaga mutu ikan segar sebagai bahan baku pemasaran ikan segar (Pandit. I G. S., 2017). Keselamatan kerja menjadi hal utama dimana Kesehatan dan Keselamatan Kerja atau K3 diatur dalam Undang-undang Ketenagakerjaan. Berupa menggunakan Alat Pelindung Diri (APD) (Kementerian Kesehatan Republik Indonesia. 2019). Metode pengabdian masyarakat yang dilakukan berupa penyuluhan, dan demonstrasi plot.

\section{METODE}

Pemilihan lokasi PkM di Kedonganan didasari atas Desa ini merupakan aktivitas pemasaran ikan segar dari berbagai daerah termasuk juga ikan didatangkan dari Banyuwangi dan daerah sekitar.

PkM diawali dengan observasi ke lokasi serta dialog singkat terhadap pihak pengelola pasar ikan Kedonganan melalui KUD Mina Sari Segara. Berdasarkan hasil tersebut diperoleh 3 masalah utama yang dialami oleh pedagang ikan segar di Desa Kedonganan meliputi penanganan bahan baku ikan segar, kesehatan para pedagang ikan di era new normal serta pengelolaan wisata kuliner. Untuk mengatasi masalah penanganan ikan segar dilakukan penyuluhan dan demontrasi plot penerapan metode cold chain system untuk mempertahankan ikan tetap segar selama pemasaran. Untuk penanganan masalah kedua dengan melakukan pelatihan Kegiatan kedua yaitu memberikan simulasi pemakaian alat pelindung diri, mulai cara mencuci tangan, pemakaian masker, sarung tangan, apron, sepatu boat untuk meningkatkan keamanan serta melindungi diri saat bekerja. Disamping itu juga diberikan penyuluhan tentang pengelolaan wisata kuliner yang sesuai dengan kesepakatan Desa Adat yang telah disepakati. Untuk melihat kehadiran peserta pada setiap kegiatan dilakukan evaluasi berupa pre-test 
dan post-test, Pre-test dilakukan sebelum kegiatan dan post-test setelah kegiatan selesai. Pre-test dan post-test yang diberikan berupa 15 pertanyaan pilihan ganda terkait dengan materi di atas. Peningkatan nilai post-test kemudian dilihat secara statistik dengan menggunakan paired t-test.

\section{HASIL DAN PEMBAHASAN}

Pelaksanaan kegiatan PkM, dilaksanakan hari Selasa tanggal 11 Agustus 2021 sesuai dengan rencana yang telah disepakati, dengan membawa seluruh perlengkapan yang telah disiapkan dan dibantu oleh 2 orang mahasiswa yang berperan aktif untuk membantu menyiapkan demplot penanganan ikan segar dengan hancuran es serta contoh pemakaian APD yang benar. Acara penyuluhan PkM dilakukan di ruang pertemuan Koperasi Unit Desa Mina Sari Segara Kedonganan yang telah disiapkan dengan dihadiri oleh pengurus KUD, para pedagang ikan segar dan nelayan sejumlah 15 orang yang bersedia untuk mengikuti acara penyuluhan yang telah disepakati seperti gambar dibawah ini.

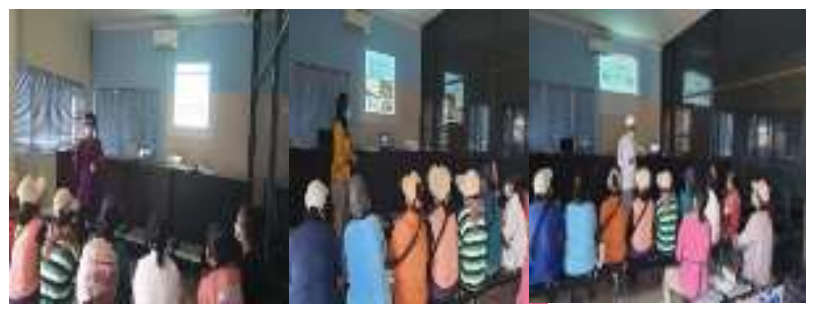

Gambar 2. Pemberian pelatihan

Materi penyuluhan meliputi mutu ikan segar, dimana ikan memiliki sifat yang highly perisable food, yaitu produk yang cepat mengalami pembusukan, sehingga kesegaran ikan perlu dipertahankan dengan sifat-sifat seperti baru diangkat dari air. Prinsip penanganan ikan segar adalah 3C + Q, yaitu Clean (bersih), Carefull (hatihati), Cool Chain (rantai dingin), dan Quick (cepat). Metode umum dalam menyimpan ikan dengan es, dengan perbandingan 1:4 atau 1:1 sudah cukup untuk memperolah ikan tetap segar (Nurachsan., 2015). yaitu: shelfing yang dapat dilakukan untuk ikan-ikan berukuran besar. Ikan yang satu dengan yang lain harus dibatasi dengan es, dan tidak bersentuhan dengan badan ikan yang lain (Pandit. I G.S., $d k k$. 2012) Ikan disusun dalam rak-rak yang hanya menampung satu lapis. Selama tranportasi ikan segar dilakukan dengan pendinginan ikan dengan udara dingin umumnya digunakan untuk pengangkutan ikan dengan mobil bok berpendingin (chiller boxes), kontainer berpendingin (reefer container). Sedangkan untuk penyimpanan ikan dalam waktu yang lama dipergunakan ruang dingin (chilled room/cool room) (Lovi. S, dan Husnur. R., 2015).

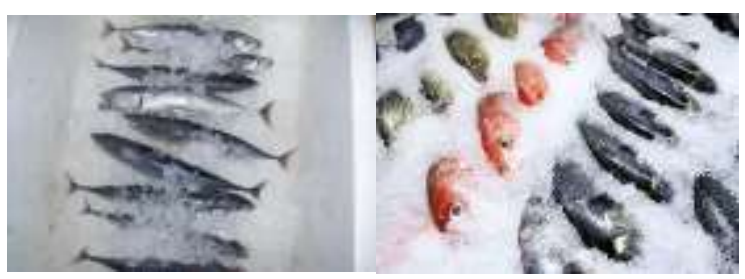

Gambar 3. Demontrasi plot penanganan ikan segar dengan es

Monitoring dan evaluasi PkM ini dilakukan pada tanggal 28 Juni 2021 untuk mengetahui apakah PkM dengan materi dan demplot yang telah diberikan pada saat penyuluhan penanganan ikan segar pada pemasaran ikan di KUD Mina Segara, serta pemakaian APD selama pemasaran ikan segar telah dilaksanakan. Berdasarkan hasil monitoring dan evaluasi seperti gambar 4, bahwa para pedagang telah menggunakan APD dengan baik dan benar.

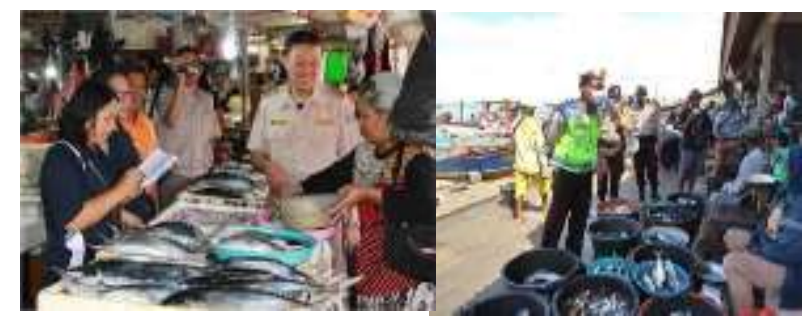

Gambar 4. APD sebelum dan setelah pelatihan

Selama kegiatan berlangsung, antusiasme peserta cukup baik, terbukti dengan kehadiran peserta untuk setiap kegiatan. Materi penyuluhan pertama adalah mengenai metode cold chain system Pada Penanganan ikan segar pada pemasaran ikan segar yang berasal dari ikan laut. Manajemen bahan baku ikan ini sangat penting mengingat ikan laut merupakan komoditi yang sangat mudah dan cepat rusak (Chintagari. S., $d k k$. 2017). Bahan baku yang melimpah harus disimpan dalam suhu dan dengan 
perlakuan yang tepat agar bisa dimanfaatkan dengan baik ketika bahan baku produksi menurun. Penanganan ikan segar ini juga meliputi bagaimana suhu ikan harus selalu dijaga pada suhu yang tepat dari proses penangkapan iakn sampai ke tangan konsumen untuk menjamin kualitas dan kesegaran ikan (Mercier. S., $d k k$. 2017). Materi kedua terkait pemakaian APD dan menjaga kebersihan selama proses pemasaran ikan segar serta dilakukan demonstrasi plot Penanganan ikan segar dengan hancuran es. Materi terkait dengan menjaga kebersihan, berupa sanitasi dan higienisitas yang penting sekali untuk diperhatikan oleh pedagang ikan segar untuk mencegah terjadinya kontaminasi (Zairinayati., $d k k$. 2020). Higiene dan sanitasi merupakan hal yang saling berkaitan dan harus diperhatikan mulai dari penanganan bahan baku ikan segar, penyimpanan, transportasi, pengolahan, pemasaran harus memperhatikan higienisitas dan sanitasinya (Pandit, I G. S., dan Permatananda, P. A. N. K., 2018).(Permatananda, P. A. N. K., $d k k$. 2019). Materi penyuluhan tentang pengelolaan wisata kuliner yang sesuai dengan kesepakatan Desa Adat yang telah disepakati untuk menjaga keasrian dan kesinambungan wisata kuliner. Bali sebagai daerah tujuan wisata, khususnya Desa Kedongann yang memiliki potensi pariwisata sebagai tempat pendaratan ikan, pemasaran ikan segar di pasar ikan segar yang dikelola oleh Desa Adat, serta tempat wisata kuliner dengan berbagai masakan berbasis ikan. Penataan berbagai aktivitas tersebut perlu dikelola dengan baik, serta perlu diatur dengan berbagai kesepakatan seluruh komponen,

Keberhasilan kegiatan juga ditinjau dengan melihat peningkatan jumlah nilai benar pada posttest dibandingkan dengan pre-test, yang dapat dilihat pada Gambar 5. Soal yang diujikan berjumlah 15 soal pilihan ganda dengan rincian 5 soal mengenai penanganan ikan segar, 5 soal terkait proses pemakaian APD yang baik dan benar, dan 5 soal terakhir tentang aspek hygiene dan sanitasi dalam pemasaran ikan segar serta pengelolaan wisata kuliner berbasis ikan yang dikelola Desa Adat kepada 5 peserta secara acak. Hasil nilai pretest dan post-test tersebut kemudian dilakukan analisis dengan menggunakan paired t-test dan didapatkan rata-rata nilai pre-test adalah 6,40 dan rata-rata nilai post-test adalah 14,40 dengan rerata peningkatan sebesar 8 poin yang bermakna signifikan secara statistik (nilai $\mathrm{P}<0,05$ ). Berdasarkan peningkatan tersebut bahwa masyarakat para pedagang ikan segar telah memahami terhadap hal yang telah disampaikan.

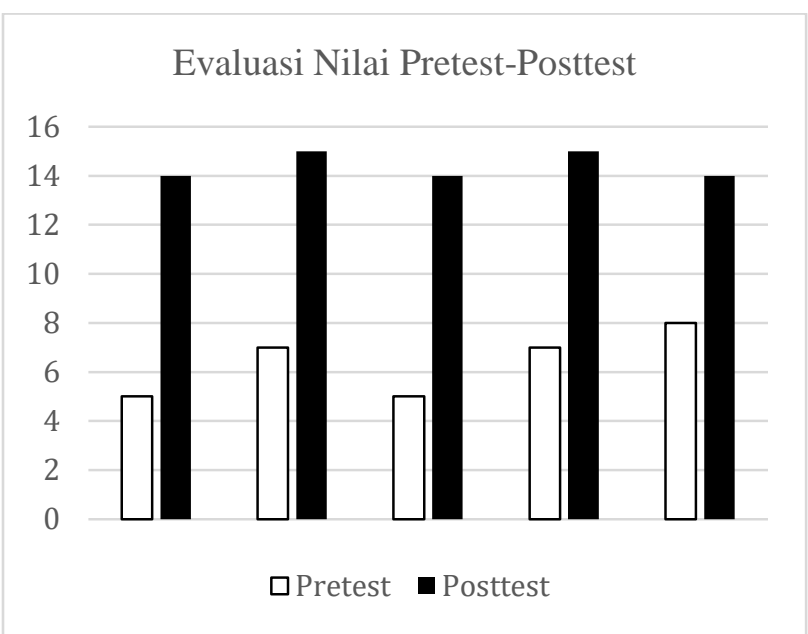

Gambar 5. Nilai Pre-test dan Post-test

Untuk keberlanjutan kegiatan PkM diperlukan sarana cool box untuk memperoleh mutu ikan segar yang baik, sehingga diperlukan pemahaman secara kontiniu untuk dapat merubah mainset para pedagang ikan segar.

\section{KESIMPULAN}

Kegiatan PkM Peningkatan Mutu Penanganan Ikan Segar Di Pasar Kedonganan Di Era New Normal di KUD Mina Segara Desa Kedonganan telah berlangsung dengan baik dan lancar dibuktikan dengan kehadiran peserta yang terdiri dari pedagang ikan segar mengikuti semua kegiatan ini dari awal hingga akhir. Metode kegiatan ini meliputi penyuluhan dan demonstrasi plot tentang penanganan ikan segar serta pemakaian APD telah dilaksanakan sesuai rencana. Evaluasi peningkatkan pemahaman pedagang tentang penanganan ikan segar dengan penerapan cold chain system serta pemakaian APD dengan baik dan benar selama melakukan pemasaran ikan segar telah berhasil dengan bermakna signifikan.

\section{UCAPAN TERIMAKASIH}




Kami mengucapkan terima kasih kepada
Lembaga Pengabdian Masyarakat $\begin{array}{r}\text { (LPM) } \\ \text { Universitas Warmadewa yang sudah mendukung }\end{array}$
penyelenggaraan kegiatan ini. Terima kasih juga
kepada kepada mitra yaitu KUD Mina Segara serta
pedagang ikan segar yang sudah berpartisipasi
sehingga seluruh kegiatan Pkm Peningkatan Mutu
Penanganan Ikan Segar Di Pasar Kedonganan Di
Era New Normal dapat berjalan dengan sukses dan
lancar.

\section{REFERENSI}

Chintagari S., Hazard, N., Edwards, G., Jadeja R., Janes, M. (2017). Risks Associated with Fish and Seafood. Microbiol. Spectrum 5 (1): $1-16$.

Kementerian Kesehatan Republik Indonesia. (2019). Penyuluhan Keamanan Pangan (PKP) Industri Rumah Tangga Pangan (IRTP) Bagi Tenaga Kesehatan Di Wilayah Kerjanya. Modul. Dit. Produksi dan Distribusi Kefarmasian, Kementerian Kesehatan RI Jakarta.

Lovi. S, dan Husnur. R., (2015). Proses Pembekuan Fillet Ikan Anggoli Bentuk Skin On Di Cv. Bee Jay Seafoods Probolinggo Jawa Timur. Samakia: Jurnal Ilmu Perikanan Volume 6, No. 1.

Mercier, S., Villeneuve, S., Mondor, M., Uvsal, I. (2017). Time-Temperature Management Along the Food Cold Chain: A Review of Recent Developments. Comprehensive Reviews in Food Science and Food Safety 16: 647-667.

Nurachsan. (2015). Teknik Penanganan Ikan Segar Dan Ikan Beku Di Atas Kapal Long Line Di Km. Sari Segara 07 Benoa Bali Jurusan Penangkapan Ikan Politeknik Pertanian Negeri Pangkep.

Pandit, I G.S., N. T. Suryadhi, I. B. Arka, N. Adiputra. (2012). The Effect Of Dressing And Storage Temperature On Chemical,
Microbiological And Organoleptic Quality Of Frigate Mackerel Fish (Auxis tharzard, Lac). E-Jurnal Medika Udayana Volume 1 No 2.

Pandit. I G.S., (2017). Application of Different Fresh Fish Handling Technique on the Quality of Raw Ingredients of Pindang Production. Jurnal Perikanan Universitas Gadjah Mada, vol 19, pp 89-96.

Pandit, I G. S., dan Permatananda, P. A. N. K. (2018). Improving Hygiene and Sanitation Behavior among Pemindang Workers in Kusamba Village Through Direct Training and Demonstration Plot. Denpasar: International Conference of Social Science European Alliance Innovation.

Permatananda, P. A. N.K., Pandit, I.G.S., Irianto, I.K. (2019). Hygiene and Sanitation in Central Pemindangan of Bali. IOP Conf. Series: Earth and Environmental Science 347012096

Zairinayati, Novianty, Garmini, R., Purnama, R., Shatriadi, H., Maftukhah, N.A. (2020). Analysis of Application Hygiene Principles of Food and Safety Employees Tofu Factory in Padang Selasa, Bukit Besar Palembang. Journal of Physics: Conference Series 1477072017. 